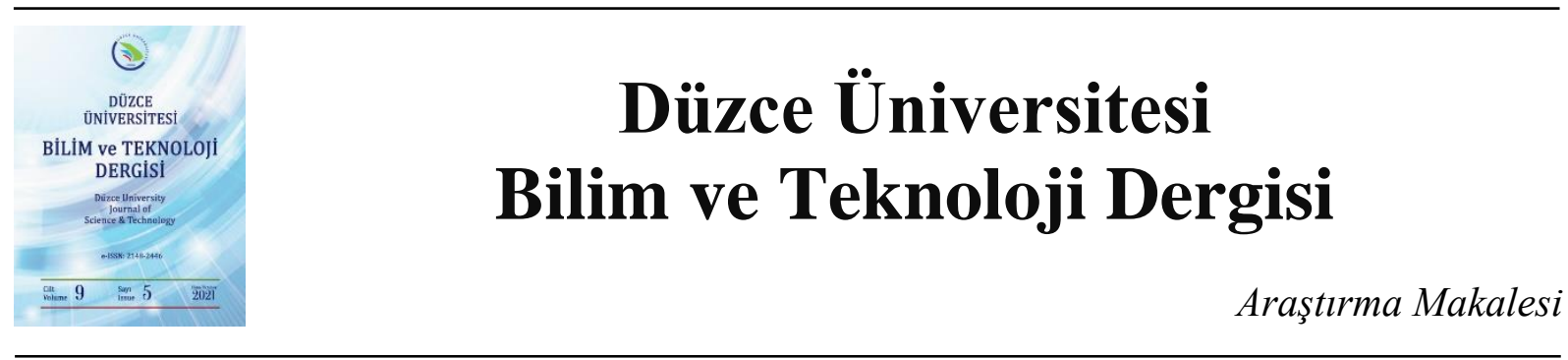

\section{Adli Bilişim İncelenme Süreçlerinde Yapay Zeka Kullanımı: VGG16 ile Görüntü Sinıflandırma}

\author{
(iD İsrafil DİLBER ${ }^{\mathrm{a}, *}$, (iD Aydın ÇETİN ${ }^{\mathrm{b}}$ \\ ${ }^{a}$ Bilişim Enstitüsü, Gazi Üniversitesi, Ankara, TÜRKIYE \\ ${ }^{b}$ Teknoloji Fakültesi, Gazi Üniversitesi, Ankara, TÜRKIYE \\ * Sorumlu yazarın e-posta adresi: israfil.dilber@gazi.edu.tr
}

DOI: 10.29130/dubited.897437

\begin{abstract}
$\ddot{\mathrm{O} Z}$
Son y1llarda teknolojide meydana gelen gelişmelerle beraber başta internet ve sosyal medya olmak üzere bulut bilişim, akıllı telefon ve navigasyon sistemleri gibi uygulamaların kullanım oranları artmıştır. İnternet ve bilişim cihazlarının yoğun kullanımı, beraberinde depolanan veya aktarılan veri miktarını arttırmış ve bu artış aynı zamanda dijital dünya ile ilişkilendirilen suç oranının da yükselmesine neden olmuştur. İşlenen suçlara ilişkin elde edilen delil boyutu da paralel olarak artmış ve artan veri miktarı, adli bilişim uzmanlarının mevcut imkânlarla veriyi analiz edebilmesini zorlaştırmıştır. Adli bilişim veri inceleme süreçlerinde yaşanan aksamalar nihai olarak adli yargılama süreçlerini de olumsuz etkilemiştir. Söz konusu sorunların giderilmesi kapsamında makalede, elde edilen görüntü verilerinin hızlı ve doğru olarak analiz edilmesini sağlayan bir model önerilmiştir. Önerilen model, VGG16 ağ yapısı ile görüntü sınıflandırma için özel tasarlanan ağ katmanlarından oluşmaktadır. Çalışmada, 2085'i Kaggle platformundan 915'i farklı kaynaklardan oluşturulan 300*300 piksel çözünürlüklü resimlerden oluşan veri seti kullanılmıştır. Model, FloydHub ortamında Keras ve TensorFlow kütüphaneleri ile test edilmişstir. Test sonuçlarına göre modelde \%97.8 doğruluk oranı elde edilmiştir. Elde edilen sonuç, benzer çalışmalarla kıyaslanmış ve önerilen modelin diğer çalışmalara oranla ortalama \%5 oranında performans artışı sağladığı görülmüştür.
\end{abstract}

Anahtar Kelimeler: Adli bilişim, Yapay zeka, Derin öğrenme, Evrişimsel sinir ă̆ları, ESA

\section{Artificial Intelligence in Digital Forensics Investigation Processes: Image Classification with VGG16}

\begin{abstract}
With the recent developments in technology, the usage rates of cloud computing, smartphones, and navigation systems, especially the internet and social media, have increased. The intensive use of these devices has increased the amount of data stored or transferred. Such an increase has also led to a growth in the digital world-related crime rate. The size of the evidence has grown incrementally, and making it difficult to analyze the data effectively. The failures in analysis processes have ultimately affected the judicial proceedings negatively. To solve the aforementioned problems, a model is proposed that enables fast and accurate analysis of image data in the article. The model consists of VGG16 convolutional and fully connected neural network layers. In the study, a data set consisting of 300x300 pixel resolution images, 2085 of which were compiled from the Kaggle platform and 915 from different sources, was used. The model was tested in the FloydHub with the Keras and TensorFlow libraries. According to the test results, a $97.8 \%$ accuracy rate was obtained. Test results indicate that the proposed model provides an average performance increase of $5 \%$ compared to other studies.
\end{abstract}

Keywords: Digital forensics, Artificial intelligence, Deep learning, Convolutional neural networks, CNN 


\section{GIRIS}

Dijital bellek kapasitelerinin devamlı artışı ile bu cihazların günlük hayatta herkes tarafından yaygın kullanımı, söz konusu cihazların incelenmesine olan ihtiyacı ve aynı zamanda incelenecek veri miktarını da artırmıştır. Bu soruna ek olarak, mevcut adli bilişim yazılımları büyük miktarda verinin analizi ve özellikle son bulguların ilişkilendirilmesi söz konusu olduğunda yetersiz kalmaktadırlar. Sonuç olarak, adli bilişim uzmanlarının analize ayırdıkları zaman gereğinden fazla olmaktadır [1]. Bunun neticesinde ise dijital delil analiz çalışmalarına paralel olarak ilerleyen yargılama süreçlerinin aksaması söz konusu olmaktadir.

Verinin gerçek değeri, karar vermede yardımcı olabilecek yararlı bilgiler üretme becerisine dayalı olarak doğrulanır. Çoğu durumda, dijital adli analiz, analistlerin veya yaygın olarak e-suç araştırmacılarının bazı araçların yardımıyla, veriye ilişkin analizini açıklamak için raporlar ve özetler oluşturdukları geleneksel ve manuel bir süreçtir. Bununla birlikte araştırmacısının, toplanan verilerle ilgili yararlı bilgileri orijinal biçiminde kavraması zor olabilir. Bu nedenle toplanan veriler SANS SFIT, Sleuth Kit, Last Activity View gibi araçlar kullanılarak anlaşılır bir forma dönüştürülebilir [2]. Bu noktada hâlihazırda kullanılan yazılım ve cihazlar metin formatında aramalar, hash değeri karşılaştırmaları vb. işlemlerde etkin olarak kullanılabilse de, söz konusu görüntü verilerinin analizi olduğunda bu cihazlar çoğu zaman yetersiz kalmaktadırlar.

Adli bilişim uzmanlarının manuel olarak görüntü verilerini incelemeye çalışmaları, görüntü başına harcanan zaman birimini artırmakta, analiz hata payını yükseltmektedir. Bilindiği üzere son zamanlarda derin öğrenme teknikleri, görüntü manipülasyonunu tanımlamak için kullanılmış ve tatmin edici sonuçlar vermiştir [3]. Dolayısı ile adli bilişim uzmanlarının veri inceleme süreçlerinde karşılaştıkları zorlukların giderilmesi maksadı ile makalede, görüntü verilerinin hızlı ve doğru sınıflandırılmasını sağlayacak, derin öğrenme algoritmalarını kullanan bir model oluşturulmuştur. Çalışmada kullanılan farklı hiper parametreler ile bu parametrelerin neticesinde elde edilen sonuçlar, derin öğrenme alanında gerçekleştirilen diğer çalışmalarda kullanılan hiper parametre ve elde edilen sonuçlar ile karşılaştırılarak değerlendirilmiştir.

Bilişim suçları ve bilişim yoluyla işlenen suçlar ile daha etkin bir şekilde mücadele edilebilmesi için, suçların aydınlatılması ve suçluların adli makamlara teslim edilmesi sürecinde fiziksel delillerden çok, elektronik veya manyetik bir ortam üzerinden iletilen veya bu ortamlara kaydedilen delil niteliği taşıyan veri ve bilgiler olarak tanımlanan dijital delillere ihtiyaç duyulmaktadır [4]. Dijital delillerin her geçen gün daha fazla önem arz ettiği mahkemelerde yargılama süreçlerinin doğru ve hızlı yapılabilmesi ancak elde edilen dijital verilerin zamanında incelenebilmesi ile mümkündür. Dolayısı ile yargılama süreçlerinin hızlandırılması ve dijital delil kaynaklı ortaya çıkan aksaklıkların en aza indirilmesi kapsamında ortaya konulan çalışma önem arz etmektedir.

$\mathrm{Bu}$ çalışma beş bölümden oluşmaktadır. İkinci bölümde adli bilişim ve yapay zekâ/derin öğrenme alanında yapılan önceki çalışmalar yer almaktadır. Üçüncü bölümde, çalışma kapsamında veri setinin oluşturulması, ağ modelinin belirlenmesi ve kullanılan hiper parametre ve değerleri hakkında bilgi verilmiş, çalışma boyunca izlenen yol ve yöntemler ayrıntılı olarak anlatılmıştır. Dördüncü bölümde model üzerinde test edilen hiper parametreler ve bu parametrelere ait sonuçlar sunulmuş ve elde edilen sonuçlar diğer çalışma sonuçları ile karşılaştırılarak değerlendirilmiştir. Son bölümde ise yapılan çalışmanın önemi ve sonucuna ilişkin genel bir değerlendirme yapılmıştır.

\section{LITERATÜR ARASTIRMASI}

Derin öğrenme algoritmaları farklı alanlara ilişkin yapılan çalışmalarda olduğu gibi adli bilişim alanında yapılan çalışmalarda da yaygın olarak kullanılmaktadır. Bu noktadan hareketle literatür araştırmasında özellikle son 5 yılda adli bilişim alanında derin öğrenme algoritmalarının kullanılmasına ilişkin çalışma ve uygulamalar araştırılmıştır. Araştırma neticesinde adli bilişim alanı kapsamında derin öğrenme 
algoritmalarının yoğun olarak metin verisi [5], ses verisi [6], video [7-9] ve resim [3], [10-19] verileri analizinde kullanıldığı tespit edilmiştir. Söz konusu çalışma alanlarına ek olarak yöntem iyileştirme [20,21], süreç iyileştirme ve otomasyon [22,23], saldırı tespit ve güvenlik log analizi [2], [24-25], derin ögrenme algoritmalarının yaygın olarak kullanıldı̆̆ı diğer alanlardır.

Metin verisi çalışması kapsamında, Kansagara ve Singh [5] adli bilişim cihazlarında metin araması gerçekleştirildiğinde aramaya ilişkin sonuçların tamamının gelmediğini belirtmiş ve bu sorunu aşacak bir model ortaya koymuşlardır. Modelde makine öğrenmesi yaklaşımı ile dosyaları bir araya toplamak için Kohenen kendi kendine organizasyon haritası gibi metotlardan faydalanmışlar ve metin araması konusunda iyi sonuçlar elde etmişlerdir.

Ses verisinin analizine ilişkin olarak yapılan çalışmada, ses inceleme süreçlerinde kullanılan temel konuşma işleme teknikleri ile adli bilişim kapsamında ses incelemelerinde kullanılan yazılımlar, performans açısından karşılaştırılmıştır [6]. Elde edilen sonuçlar, tablolar ile ayrıntılı olarak gösterilirken, ses analizi yapacak adli bilişim uzmanına doğru yazılımı seçme konusunda yardımcı olmak hedeflenmiştir.

Video analizi kapsamında, MP4, MOV ve 3GP formatında dijital videoların sonradan manipüle edildiğini tespit edebilen bir adli bilişim metodu önerilmiştir [7]. Önerilen metod, makine öğrenmesi teknikleri ile video düzenleme programlarının geride bıraktığı izlerin incelenmesi tekniğine dayanmaktadır. Toplamda 4979 manipüle edilmiş dijital video görüntüsünden faydalanılmış ve model beş farklı ölçüt ile değerlendirilmiştir. Elde edilen sonuçlarda Rastgele Orman modeli en yüksek performansı göstermiştir. Sosyal medya tespiti çalışmasında ise önerilen model 12 farklı sosyal medya platformunu yüzde yüz doğruluk oranı ile tespit etmeyi başarmıştır.

Bu alanda yapılan diğer bir çalışmada hız ve doğruluk açısından derin öğrenme teknolojilerini kullanan üç popüler yüz tanımlama dedektörü farklı veri setleri ile test edilmiş̧tir [8]. Elde edilen sonuçlar, görüntülerin yeniden boyutlandırılarak işleme alınmasının yüz tanıma süreçlerini hızlandırmakla beraber doğruluğunu azalttığını göstermiştir. Dual Face Shot Detector (DSFD) yüz tanıma detektörünün, yüzde 50 ve yüzde 25 yeniden boyutlandırılan görüntülere uygulandığında en iyi hız ve doğruluk oranı yakaladığı kanıtlanmıştır. Sreenu ve Durai [9] yaptıkları çalışmada ise kalabalık alanlarda vuku bulan olaylara ilişkin olarak nesne tespitinden, olay tespitine, kalabalık analizinden şiddet tespitine kadar birçok alanı incelemeye almışlardır. Tespit süreçlerinde derin öğrenme algoritmaları kullanılmış ve bu algoritmalar performans açısında karşılaştırılmıştır. Mevcut video analiz uygulamalarının, kötü hava şartları, nesnelerin üst üste binmesi, gerçek dünya dinamikleri dikkate alındığında çoğu zaman veriyi analiz etmede yetersiz kaldığı tespit edilmiş ve video analiz işlemlerinde daha iyi sonuçların alınabilmesi için mevcut derin öğrenme algoritmaları ile klasik video analiz yöntemlerinin birleştirilmesi önerilmiştir.

Görüntü verilerinin derin öğrenme algoritmaları ile incelenmesi kapsamında Fernandes, Cardoso ve Astrup [10] cinsel saldırılarda elde edilen verilerin otomatik ve objektif olarak yorumlanmasını sağlayan derin öğrenme yapısı önermişlerdir. Makine öğrenmesi ve bilgisayar görmesi teknolojilerinden faydalanılmış, çalışmada cinsel bölge yara tespitinden adli bilişim delil yorumlanmasına ve görsel teknikler ile kararın açıklanmasına kadar geniş bir alan kapsam içine alınmıştır. Cinsel saldırıya ilişkin izlerin ortaya konulması açısından klasik yöntemler ile derin öğrenme algoritmaları karşılaştırılmış ve yapılan bütün testlerde derin öğrenme algoritmalarının daha yüksek verim ortaya koyduğu anlaşılmıştır.

Görüntü verilerine ilişkin olarak diğer bir çalışmada ise Evrişimsel Sinir Ağları (ESA) algoritmasını kullanan bir adli bilişim modeli önerilmiştir [11]. Önerilen modelde, girdi olarak kullanılan resim verilerine ait gri düzey eş oluşum matrisleri ESA'yı beslemede kullanılmıştır. Önerilen model, karşı adli bilişim atakların ortaya çıkarılması kapsamında sahteciliğin doğru olarak tespiti açısından klasik modellere oranla yüksek başarı göstermiş̧ir. Bir diğer çalışmada ise dijital verilerin orijinalliği ve bütünlüğünün tespit edilmesi maksadı ile bu alanda kullanılan aktif ve pasif metotlar ile derin öğrenme algoritmalarına dayanan yöntemleri karşıllaştııılmıştır [3]. Bu çalışmada ESA tabanlı teknikler bozulmuş görüntü verilerinin tespiti kapsamında iyi sonuçlar ortaya koymuş olsa da bu alanda, karşı adli bilişim 
metotlarının da yaygın ve etkin olarak kullanıldığ 1 ve bu metotlardan da tatmin edici sonuçlar elde edildiği vurgulanmıştır. Başka bir çalışmada insanların kıyafetlerinden elde edilen görsel verileri kullanarak kimlik tespitinde bulunan bir derin öğrenme modeli önerilmiştir [12]. Sıradan kıyafet veri seti kullanarak sınıflandırma yapıldığında önerilen modelin kötü performans sergilediği fakat popüler logo ve marka isimleri barındıran görüntüler kullanıldığında önerilen modelin yüzde 75'e yakın bir başarı oranı yakaladığı tespit edilmiştir. Görüntü analizi kapsamında Olmos, Tabik, ve Herrera [13] silah görüntü verilerinin insan müdahalesine gerek kalmadan tespit edebilen bir ESA modeli önermişlerdir. Havaalanlarında kullanılan silah tespit sistemlerinin sadece metal cisimleri algıladığ 1 , X-ray tarayıcı ve yürüyen bant ile kombine ve pahalı sistemler olduğu ve neticesinde yaygın kullanımının sınırlı olduğu belirtilen çalışmada, sorunun aşılmasına ilişkin olarak VGG16 ağ modeli birçok farklı veri seti ile beraber kullanılmıştır. Çalışmada en iyi görüntü sınıflandırma algoritması olduğu tespit edilen Faster RCNN, düşük kalitede ve yedi farklı popüler filmden oluşan video verisinde de kullanılmış ve görüntülerin dinamik olmasına rağmen tatmin edici neticeler elde edilmiştir.

Görüntü analizi kapsamında yapılan diğer bir çalışmada, OpenFace uygulamaları, farklı veri setleri kullanılarak adli bilişim alanında denenmiştir [14]. İleri sürülen model ile adli bilişim süreçlerinde elde edilen yüz görüntülerinin farklılık ve benzerliklerin hangi oranda bulunabildiği üzerine yoğunlaşılmış, OpenFace algoritmasının iyi bir performans ortaya koyduğu fakat yüz görüntülerinin kalitesi düştükçe modelin etkinliğinin de düştüğü gözlemlenmiştir. OpenFace uygulamasının mevcut hali ile veri analizinde yetersiz kalacağı, geliştirilmesi halinde bu alanda umut veren gelişmelere yol açabileceği çalışmada ileri sürülmüş̧ür. "Adli benzerlik" diye isimlendirilen ve iki görüntüye ait adli izlerin aynı olup olmadığını belirleyen bir model, Mayer ve Stamm [15] tarafından ortaya atılmıştır. Modelin en önemli avantajının, adli verilerin aynı olup olmadığına karar verirken, modelin önceden benzer verilerle eğitilmesine ihtiyaç olmadığı belirtilen çalışmada, modelin doğruluğu, resim çiftlerinin aynı derleme programı ile yapıldığına karar verebilmesi çerçevesinde test edilmiştir. Modelin önceden eğitilmediği adli izlerde bile doğru çalıştığı ve önceki çalışmalara oranla hata oranını yüzde 50 azalttığı tespit edilmiştir.

Diğer bir çalışmada ise olay mahallinde kumaş parçası üzerinde bulunan barut kalıntısını otomatik olarak tespit edebilen iki farklı makine öğrenmesi algoritması ve hiperspektral kamera uygulamaları incelenmiştir [16]. Çalışmada, olay yerinde barut kalıntısının varlığının teyit edilebilmesi için her ne kadar analiz ve ikinci bir tanımlama tekniği gerektiği vurgulansa da, görüntü işleme algoritmalarını kullanan hiperspektral kameranın, delil toplama ve analiz işlemlerini destekleyen önemli bir uygulama olduğu sonucuna varılmıştır. Eriş [17] ise bu kapsamda adli bilişim veri inceleme süreçlerinde yardımcı bir eleman olarak derin öğrenme algoritmalarının kullanılmasını hedeflemiştir. Bu maksatla derin öğrenme algoritmaları kullanılarak görüntü sınıflandırma modeli oluşturmuş, görüntü verileri üzerinde yapılan sınıflandırma işlemlerinde yüzde 90 üzerinde başarı elde etmiştir.

Bu alanda yapılan bir diğer çalışmada görüntü üzerinde yapılması muhtemel sahtecilik işlemlerini ve bu işlemlerin tespitinde kullanılan bazı görüntü manipülasyon tekniklerini incelemek üzere farklı teknikler üzerinde çalışmalar gerçekleştirilmiştir [18]. Çalışma boyunca ImageNet veri setinden ve farklı derin ögrenme modellerinden faydalanırken, pratik manipülasyon tespit sisteminin oluşturulmasının zor olduğu fakat transfer öğrenme ve farklı modellerin birleştirilmesi ile manipülasyon tespit sistemi geliştirilebildiği belirtilmiştir.

$\mathrm{Bu}$ alanda yapılan son çalışmada adli bilişim veri inceleme süreçlerinde görüntü verilerinin derin öğrenme algoritmaları ile hızlı ve doğru olarak sınıflandırılması üzerine çalışılmıştır [19]. Bu kapsamda adli bilişim görüntü inceleme işleminde insan müdahalesinin en aza indirilmesi hedeflenmiş, eğitim ve doğrulama işlemleri için farklı sayıda görüntü verisi kullanılırken sınıflandırma işlemine ilişkin olarak yaklaşık yüzde 93 oranında başarı elde edilmiştir.

Yöntem iyileştirme çalışmaları kapsamında ise makine öğrenmesinin, internet sitesi saldırılarının analizi ve incelenmesi süreçlerinde etkili bir yöntem olarak kullanılabileceği önerilmiştir [20]. Çalışmada, makine öğrenmesi aşamalarında özellik seçiminin kritik olduğu ve doğru parametrelerin seçilmesi durumunda modelin performansının artacağı vurgulanmıştır. Günümüzde internet site saldırılarında 
delil elde etmek için optimal bir parametre seçimin henüz uygulamada olmadığ 1 ileri sürülmüş ve bu kapsamda filter ve wrapper metotlarını kullanan bir hibrit yöntem önerilmiştir. Önerilen modelin başarısı 3 farklı internet site saldırısı senaryosu eşliğinde kanıtlanmıştır. Bu alanda yapılan bir diğer çalışmada ise verinin adli bilişim açısından incelenmesini kapsayan ve üç aşamadan oluşan bir çalışma ortaya konmuştur [21]. İlk evrede Android akıllı telefonlara ilişkin veri analizi yapılmış ve aynı zamanda Paraben E3 ve Autopsy adli bilişim cihazlarının karşılaştırılması yapılmış ve Android cihazları üzerinde yapılan işlemlere ait izlerin bu cihazların dahili hafızasında tespit edilebileceği kanıtlanmıştır. İkinci aşamada ise Snapchat uygulamasına ait veriler, Android cihazlar üzerinde analiz edilmiş ve Snapchat üzerinde gerçekleştirilen bazı işlem verilerine Paraben E3 kullanılarak ulaşılabildiği görülmüştür. Son aşamada ise Microsoft Azure ve IBM Watson üzerinde bulunan makine öğrenmesi servisleri performansları açısından test edilmiştir.

Süreç iyileştirme ve otomasyon kapsamında yapılan çalışmada ise Rughani [22] adli bilişim veri inceleme aşamalarında insan müdahalesini en aza indirmek maksadıyla rutin işlemlerin yapay zekâ uygulamaları ile yapılması anlayışına dayanan bir model önermiştir. Önerilen modelin adli bilişim süreçlerinde ihtiyaç duyulan zamanı azalttığı, daha az işlemci gücüne ihtiyaç duyduğu, bunun yanında insan iş gücünü de azalttı̆̆ tespit edilmiş̧ir. Bu kapsamda yapılan bir diğer çalışmada yapay zekâ ve sayısal mantığın delil analizinin otomasyonunun sağlanmasında kullanılabilirliği ortaya konulmaya çalışılmıştır [23]. Çalışmada, insan eli ile çözülmesi zor olan veri inceleme süreçlerinin, optimizasyon problemi gibi ifade edilebileceği ileri sürülmüss, kanıt olarak sayısal mantık programları ile gerçek soruşturma vakalarının formalize edilebildiği ve bir metodolojinin somut inceleme hipotezini nasıl formüle ettiği gösterilmiştir.

Saldırı tespitinin yapılabilmesi ve log analizi incelenmesi alanında yapılan çalışmada adli bilişim süreçlerinde delillerin ortaya çıkarılması maksadı ile makine öğrenmesi algoritmaları aracıllğıyla sistem dosyalarına ait güvenlik kayıtlarını inceleyerek bu kayıtların başka uygulamalar tarafından manipüle edilip edilmediği tespit edilmeye çalışılmıştır [2]. Çalışmada word, excel gibi on farklı program izi kullanılarak yaklaşık 42 bin adet veri elde edilmiş, bu veriler ile farklı derin öğrenme algoritmaları eğitilmiş ve en iyi sonuç YSA ve rastgele orman algoritmaları ile elde edilmiştir. Log analizi kapsamında yapılan bir diğer çalışmada Pandey, Mujmer, Gyarsiya ve Kanungo [24] zararlı yazılımların tespit edilmesine ilişkin olarak yapılan çalışmaları ve adli bilişim alanında mevcut sorun sahalarını ortaya koymuşlardır. Çalışmada, makine öğrenmesi algoritmaları zararlı yazılımların tespit edilmesi açısından değerlendirilmeye alınmış, rastgele orman algoritmasının zararlı yazılımların herhangi bir sistem dosyası içerisinde tespit edilmesi kapsamında en etkili algoritma olduğu belirtilmiştir.

$\mathrm{Bu}$ alanda yapılan son çalışmada ise derin öğrenme algoritmalarının siber saldırıya karşı koymada yardımcı eleman olarak kullanılabileceği ileri sürülmüş ve bu maksatla derin öğrenme, akıllı hesaplama tekniklerini kullanan ve Deep Learning Cyber Forensics (DLCF) olarak adlandırılan bir jenerik çatı sunulmuştur [25]. Çalışmada, derin öğrenme algoritmalarının birçok alanda kullanıldığı dolayısı ile bu teknolojinin siber adli bilişim alanında vakaların tespit edilmesi, veri boyutunun minimum seviyelere indirilmesi ve sonuçların doğru yorumlanması aşamalarında da uygulanabileceği belirtilmiştir.

\section{MATERYAL VE YÖNTEM}

Mevcut adli bilişim veri inceleme cihaz ve yazılımları özellikle görüntü verileri söz konusu olduğunda otomatik olarak inceleme ve yorumlama konusunda yetersiz kalmaktadırlar. Bu noktada adli bilişim uzmanlarına veri inceleme süreçlerinde destek olacak ve özellikle görüntü verilerinin hızlı ve doğru incelenmesini sağlayacak bir görüntü sınıflandırma modeli önerilmiştir. Bu bölümde çalışmada kullanılan veri seti, ağ modeli ve hiper parametreler hakkında bilgi verilmiş ve çalışma boyunca takip edilen süreç, genel hatları ile Şekil 1'de sunulmuştur. 


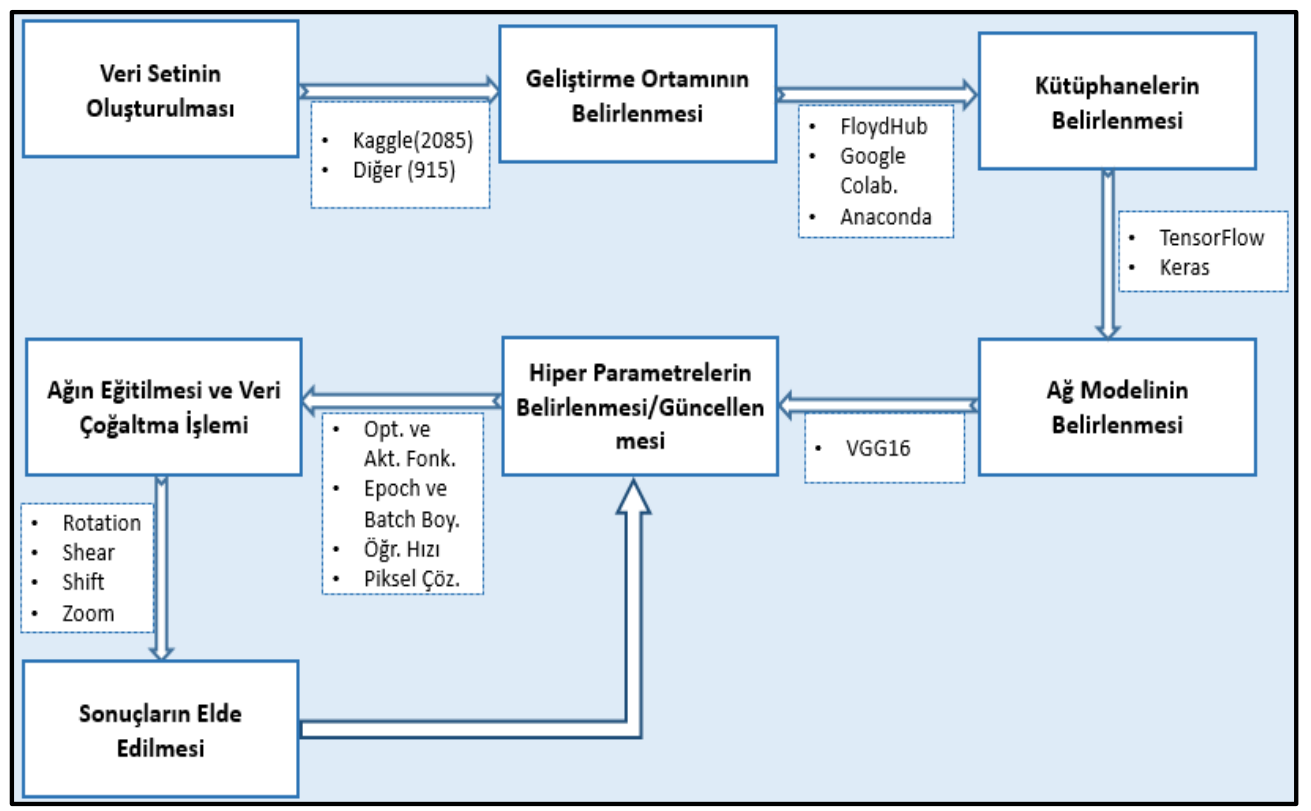

Şekil 1. Önerilen modele ait süreç akış diyagramı

\section{A. VERI SETININ OLUȘTURULMASI}

Derin öğrenme alanında yapılan çalışmalarda ağ modelini eğitmek maksadı ile ImageNet, Coco ve Mnist gibi birçok veri seti kullanılmaktadır. Bu kapsamda makalede, binlerce farklı kategoride geniş veri seti yelpazesine sahip Kaggle platformu temel veri seti kaynağı olarak kullanılmıştır. Veri seti oluştururken, Kaggle veri seti yanı sıra farklı arama motorlarından elde edilen görüntülerden de faydalanılmıştır. Makalede 1500 tabanca ve 1500 biçak görüntüsü olmak üzere toplamda 3000 görüntü verisi kullanılmıştır. Elde edilen görüntülerin 2000 adedi eğitim maksadı ile kullanılırken 1000 adedi ise doğrulama amacı ile kullanılmıştır. Tabanca görüntülerinin tamamı Kaggle platformundan [26-28] elde edilirken, bıçak görüntülerinin sadece 585 adedi Kaggle platformundan [29-30] elde edilmiş, 915 adet görüntünün elde edilmesinde ise arama motorlarından faydalanılmıştır.

Veri çoğaltma işlemi, mevcut görüntülerin farklı işlemlerden (çevirmek, daraltmak, döndürmek vb.) geçirilerek yeniden ağın eğitilmesinde kullanılmasıdır. Bu kapsamda çalışmada yaygın olarak tercih edilen $\% 20$ oranında rotation, shear, shift, zoom ve horizontal flip gibi veri çoğaltma tekniklerinden faydalanılmıştır.

\section{B. GELIŞTİRME ORTAMI VE KULLANILAN KÜTÜPHANELER}

Farklı programlama dillerinde yazılan ücretli veya açık kaynak kod olarak kullanılabilecek başlıca derin öğrenme geliştirme ortamları; Anaconda, Neural Disegner, FloydHub, Deep Learning Studio, Google Colaboratory ve Deep Learning Kit olarak sıralanabilmektedir. Çalışma kapsamında yerel bilgisayarda Anaconda geliştirme ortamı denenirken, Google Colaboratory ve FloydHub'in hem ücretli hem de ücretsiz bulut bilişim hizmetleri de test maksadı ile kullanılmıştır. Bununla beraber hem süre açısından avantaj sağlaması hem de kullanıcı odaklı olması nedeni ile çalı̧̧ma boyunca ağırlıklı olarak FloydHub (GPU-62) geliştirme ortamı tercih edilmiştir.

Derin öğrenme uygulamalarında araştırmacılar tarafından yaygın olarak Keras, TensorFlow, Theano veya Pytorch gibi derin öğrenme kütüphaneler kullanılmaktadır. Bu kapsamda farklı platformlar ile sorunsuz çalışması, birbiri ile olan uyumu ve yaygın kullanımı sebebi ile Keras ve TensorFlow kütüphaneleri çalışmada tercih edilen kütüphaneler olmuştur. Keras, araştırmacılara ağ katman sayısı, hata ve optimizasyon fonksiyonu seçimi vb. konularda bilgi sunan fakat düşük seviye operasyonları desteklemeyen bir çatı kütüphane konumundadır. Bununla beraber Keras, kod değiş̧ikliğine ihtiyaç duymadan TensorFlow, Theano veya CNTK gibi düşük seviye kütüphanelerle uyum içerisinde 
çalışabilmektedir. Google firması tarafindan geliştiren TensorFlow ise kolayca farklı projelere adapte edilebilen, ölçülebilir ve hızlı işlem gücüne sahip açık kaynak kodlu bir kütüphanedir.

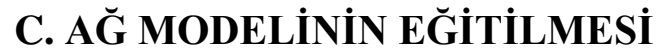

Derin öğrenme çalışmalarında başarı oranını artırmak için önceden milyonlarca farklı veri ile eğitilmiş ağ yapılarını kullanmak yaygın olarak tercih edilen bir yöntemdir. Transfer öğrenmesi (transfer learning) olarak isimlendirilen bu yöntem kapsamında genellikle VGG16, LeNet veya ILSVRC gibi ağ modelleri kullanılmaktadır. Söz konusu ă̆ modelleri ESA ve tam bağlı (fully connected) Yapay Sinir A ̆̆ı (YSA) olmak üzere iki farklı bölümden meydana gelmektedir. ESA aşamasında veriye ait özellik çıkarımı gerçekleştirilirken YSA bölümünde ise verinin sınıflandırılması sağlanmaktadır. Dolayısı ile makalede görüntü sınıflandırma alanında yaygın olarak kullanılan ve yüksek başarı oranı sağlayan VGG16 ağ modeli kullanılmıştır. VGG16 ağ modelinin ESA katmanı yeniden eğitilmeden olduğu gibi aktarılırken, sınıflandırma işleminin gerçekleştirilmesi için üç katmanlı yeni bir ağ yapısı oluşturulmuştur. VGG16 ağ modelinde toplamda 14 milyondan fazla değişken yer almaktadır. VGG16 ağ yapısı ve eklenen katmanlara ilişkin model özeti Şekil 2'de sunulduğu gibidir.

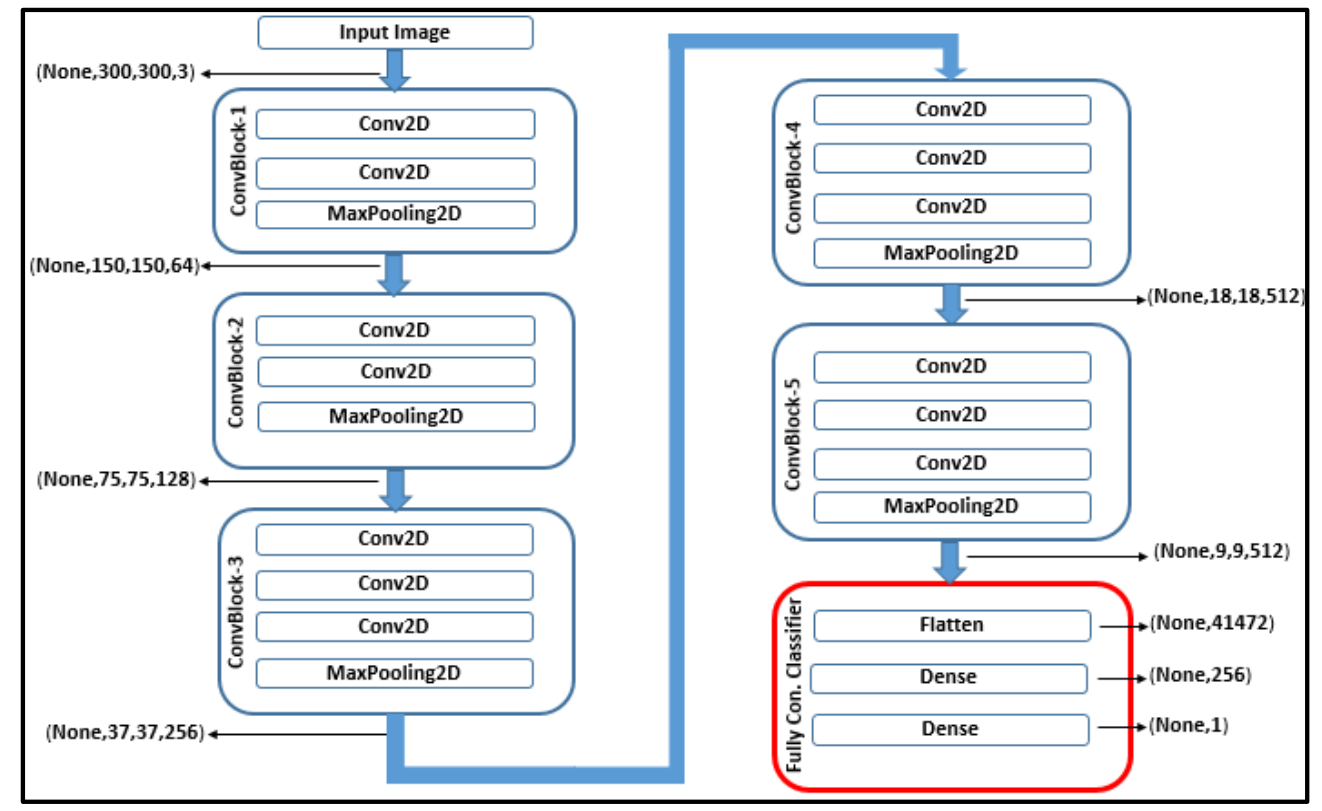

Şekil 2. Önerilen ăg modeli

A $\breve{g}$ modeli oluştururken kullanılabilecek çok sayıda hiper parametre mevcuttur. Farklı hiper parametrelerin olması model oluştururken ana mimariyi değiştirmeden araștırmacılara model üzerinde değişiklik yapma imkânı tanımaktadır. Hiper parametrelerin kapsamı oldukça geniştir. Basit bir model oluştururken dahi ağ katman sayısı, katmanlarda kullanılacak fonksiyon türü veya eğitilecek ağırlık sayısına kadar birçok hususa karar vermek gerekmektedir. Hiper parametreler ağ modelinin başarısı için kritik öneme sahiptir. Söz konusu parametrelerde yapılacak en ufak değişiklikler modelin başarısını doğrudan etkileyebilmektedir. Modelin başarısı için en uygun hiper parametreye karar vermek zordur. En iyi parametre değerleri modele bağlı olarak değişkenlik gösterdiğinden, ancak deneme yanılma yolu ile bulunabilmektedir. Bu kapsamda çalışmada en iyi sonuçların alınabilmesi için farklı hiper parametre bileşenleri ve bu bileşenlere ait farklı değerler test edilmiş ve elde edilen sonuçlara bağlı olarak hangi hiper parametrelerin kullanılacağına karar verilmiştir.

\section{HİPER PARAMETRELERIN SEÇIMI}

Derin öğrenme algoritmalarında kullanılan aktivasyon fonksiyonunun temel işlevi, ağırlık değerlerinin hesaplayarak ilgili nöronun aktif edilip edilmemesine karar vermektir. Aktivasyon fonksiyonu, üstlendiği rol gereği yapay sinir ağları tarafından doğrusal olmayan gerçek dünya problemlerinin 
çözülebilmesini olanaklı hale getirmiştir. Bu kapsamda gizli katman ve çıktı katmanında yaygın olarak kullanılan farklı aktivasyon fonksiyonları test edilmiş ve elde edilen sonuçlar Bölüm IV’te sunulmuştur.

Optimizasyon fonksiyonu, ağda yer alan ağırlık değerlerinin geri yayılım (back propagation) yöntemi ile güncellenmesi başta olmak üzere ağın eğitilmesinden, hata değerinin ortaya çıkarılmasına kadar birçok hususu kapsamaktadır. Ana işlevi hata değerinin en aza indirgenmesi olan optimizasyon fonksiyonunun seçimi kadar önemli bir diğer husus ise hata fonksiyonunun seçimidir. Lokal minimum içeren hata fonksiyonları seçilmesi durumunda optimizasyon fonksiyonunun yanılma ihtimali her zaman vardır. Günümüzde çalışmalarda yaygın olarak Ada Delta, OLSİ, ADAM, SGD veya AdaGrad gibi optimizasyon fonksiyonları kullanılmaktadır. Çalışma kapsamında test edilen optimizasyon fonksiyonları ile bu testlerde elde edilen sonuçlar Bölüm IV'te sunulmuştur.

Loss fonksiyonu tahmin edilen sonuç ile elde edilen sonuç arasındaki farkı ortaya koyması nedeni ile modelin ne derece doğru çalıştı̆̆ını gösteren fonksiyondur. Cost fonksiyonu olarakta isimlendirilen bu fonksiyon, başlangıçta belirlenen ve müteakiben güncellenen ağırlık değerlerinin belirlenmesinde önemli role sahiptir. Özellikle geri yayılım tekniğinin doğru uygulanabilmesi için bu fonksiyonun doğru seçimi oldukça önemlidir. Derin öğrenme alanında çalışma yapan araştırmacıların yaygın kullandığı loss fonksiyonlar1 Mean Squared Error, Cross Entropy veya Categorical Hinge olarak siralanmaktadır. Bu kapsamda çalışmada test edilen loss fonksiyonları ve elde edilen sonuçlar Bölüm IV’te sunulmuştur.

Öğrenme hızı, geri yayılımı müteakip ağda bulunan ağırlıkların hangi oranda güncelleneceğini belirleyen hiper parametredir. Değerinin büyük olması modelin en iyi çözüm noktasından uzaklaşmasına sebebiyet verirken, düşük olması ise ağın eğitilme sürecinin uzamasına ve modelin uygulanabilirlikten uzaklaşmasına neden olabilmektedir. Çalışma kapsamında farklı öğrenme hızları test edilmiş ve en yüksek başarı oranı 0.00002 değeri ile elde edilmiştir.

Veri setinde yer alan bütün görüntülerin ağ modelinin tamamından bir defa geçmesi işlemi epoch sayısı ile ifade edilir. Ağ katmanlarının yeterli seviyede eğitilmesi ancak epoch sayısının arttırılması ile mümkündür. Epoch sayısının gereğinden yüksek değere sahip olması aşırı beslenmeye (overfittig) neden olurken, düşük değerde olması ise ağın yetersiz eğitilmesine sebebiyet verebilmektedir. $\mathrm{Bu}$ kapsamda çalışmada farklı epoch değerleri test edilmiş ve en iyi sonuç 30 değeri ile elde edilmiştir.

Ağ katmanları eğitilirken her defasında ağa gönderilen veri paket sayısı batch boyutu olarak adlandırılır. Batch boyutuda diğer hiper parametrelerde olduğu gibi ağın başarısını etkileyen önemli etkenlerdendir. Bu kapsamda çalışma boyunca birçok batch boyutu test edilmiş ve en iyi sonuçların 20 değeri ile elde edildiği tespit edilmiştir.

Derin öğrenme uygulamalarında ağ modelinin etkin olarak eğitilmesi için, veri setlerinde bulunan görüntülerin standart piksel çözünürlüğüne getirilmesi gerekmektedir. Bu kapsamda farklı piksel çözünürlük değerleri test edilmiş en iyi sonucun $300 * 300$ piksel çözünürlüğü ile elde edildiği gözlemlenmiştir.

\section{BULGULAR VE DEĞERLENDİRME}

Çalışma boyunca en yüksek doğruluk değerine ulaşılabilmesi için aynı model üzerinde farklı hiper parametreler ve bu parametrelere ait farkı değerler kullanılmıştır. Model test edilirken her seferinde sadece bir parametre üzerinde değişiklikler yapılmış ve bu esnada diğer parametrelere ait en iyi değerler ise sabit tutulmuştur. Sonuçlarda doğruluk oranı (accuracy) olarak ifade edilen değer, doğru sınıflandırılan görüntülerin toplam görüntü sayısına oranıdır.

$$
\text { Doğruluk Oranı }=\frac{(T P+T N)}{(T P+F P+F N+T N)}
$$


Aktivasyon fonksiyonları kapsamında çıktı katmanında en iyi değerin alındığı Sigmoid fonksiyonu sabit tutularak gizli katmanda Linear, Tanjant, Softmax ve ReLu fonksiyonları test edilmiştir. Test edilen aktivasyon fonksiyonları içerisinde Softmax fonksiyonu ile en düşük başarı oranı elde edilirken ReLu fonksiyonu ile ise en yüksek başarı oranı elde edilmiştir. Optimizasyon fonksiyonları kapsamında AdaDelta, SGD, AdaGrad, Adam ve RMSProp fonksiyonları test edilmiştir. Test edilen fonksiyonlar içerisinde en düşük başarı oranı AdaDelta fonksiyonu ile elde edilirken en yüksek başarı oranı ise RMSProp ile elde edilmiştir. Loss fonksiyonları kapsamında Categorical Hinge, Mean Squared Error, Mean Squared Logarithmic Error, Mean Absolute Error, Sparse Categorical Crossentropy, Kullback Leibler Divergence ve Binary Crossentropy fonksiyonları test edilmiştir. Test edilen fonksiyonlar arasında en düşük başarı oranı Mean Absolute Error ile elde edilirken en yükssek başarı oranı ise Binary Crossentropy ile elde edilmiştir. Bunun yanında test edilen Sparse Categorical Crossentropy ve Kullback Leibler Divergence fonksiyonlarına ilişkin anlamlı sonuçlar elde edilememiştir.

Literatür kapsamında incelenen çalışmalarda, adli bilişim veri inceleme süreçlerinde doğruluk ve hız unsurlarının geliştirilmesi yolu ile süreçlerin otomasyonun sağlanması ve bu maksatla metin, log, video ve görüntü gibi farklı formatta bulunan verileri sinıflandırarak analizini yapacak farklı modellerin geliştirildiği tespit edilmiştir. Bu kapsamda özellikle [13],[17],[19] ile ortaya konulan çalışmalarda adli bilişim süreçlerinde elde edilen görüntü verilerinin doğru sınıflandırılması ile veri inceleme süreçlerinde insan müdahalesinin en aza indirgenerek, inceleme süreçlerinin hızlandırılması ve böylece adli bilişim uzmanlarının iş yükünün azaltılması hedeflenmiştir. Bu noktadan hareketle söz konusu çalışmalarda elde edilen başarı oranı ile kullanılan hiper parametreler makalede ileri sürülen model ile karşılaştırılmış ve elde edilen sonuçlar Tablo 4 ve Tablo 5'de sunulmuştur.

Tablo 4. Çalışmalara ait ana değiş̧kenler

\begin{tabular}{|c|c|c|c|c|c|c|c|}
\hline Ref. & Veri Seti & $\begin{array}{c}\text { Görüntü } \\
\text { Sayısı }\end{array}$ & $\begin{array}{c}\text { Veri } \\
\text { Çoğaltma }\end{array}$ & Platform & Kütüphane & Model & $\begin{array}{c}\text { Transfer } \\
\text { Öğrenimi }\end{array}$ \\
\hline 13 & ImageNet & 3000 & N/A & Caffe & $\begin{array}{c}\text { Keras } \\
\text { Theano }\end{array}$ & VGG-16 & Mevcut \\
\hline 17 & $\begin{array}{c}\text { ImageNet } \\
+ \text { Web }\end{array}$ & 6660 & Mevcut & Özel & $\begin{array}{c}\text { TensorFlow } \\
\text { Cuda }\end{array}$ & $\begin{array}{l}\text { Faster } \\
\text { RCNN }\end{array}$ & Mevcut \\
\hline 19 & ImageNet & 25000 & Mevcut & Anaconda & $\begin{array}{c}\text { Keras } \\
\text { TensorFlow }\end{array}$ & Özel & $\begin{array}{l}\text { Mevcut } \\
\text { Değil }\end{array}$ \\
\hline $\begin{array}{c}\text { Önerilen } \\
\text { Model }\end{array}$ & $\begin{array}{l}\text { Kaggle } \\
+ \text { Web }\end{array}$ & 3000 & Mevcut & FloydHub & $\begin{array}{c}\text { Keras } \\
\text { TensorFlow }\end{array}$ & VGG-16 & Mevcut \\
\hline
\end{tabular}

Tablo 5. Çalışmalara ait hiper parametre ve başarı değerleri

\begin{tabular}{cccccccc}
\hline \multicolumn{7}{c}{ Hiper Parametreler } & Doğruluk \\
\hline Ref. & Epoch & Batch & Pik.Çözn. & $\begin{array}{l}\text { Opt. } \\
\text { Fonk. }\end{array}$ & Akt. Fonk. & $\begin{array}{c}\text { Loss } \\
\text { Fonk. }\end{array}$ & Oranı \\
\hline 13 & N/A* & N/A* & $1000 * 1000$ & SGD & ReLU & N/A* & $\% 91,43$ \\
\hline 17 & N/A* & N/A* & $600 * 600$ & N/A & N/A & N/A* & $\% 95,00$ \\
\hline 19 & 100 & 128 & $224 * 224$ & ADAM & Sigmoid & MAPE & $\% 93,58$ \\
\hline $\begin{array}{c}\text { Önerilen } \\
\text { Model }\end{array}$ & 30 & 20 & $300 * 300$ & RMSprop & ReLU & $\begin{array}{c}\text { Binary } \\
\text { Cross } \\
\text { Entropy }\end{array}$ & $\% 97,80$ \\
\hline
\end{tabular}


A $\breve{g}$ katmanlarında hiper parametrelerinin deneme yanılma yolu ile güncellendiği ve buna bağlı olarak başarı oranının da değiştiği, farklı parametreler ile yapılan denemeler neticesinde ortaya konulmuştur. Çalışma boyunca ağda yer alan katman ve değişken sayısı, katmanlarda kullanılan fonksiyon türleri, ağ eğitilirken tercih edilen epoch ve batch sayısı gibi hususlar üzerinde yapılan hassas değişikliklerin (fine tuning) modelin sınıflandırma performansına doğrudan etki ettiği görülmüştür. Bu kapsamda hiper parametreler üzerinde gerçekleştirilen güncellemeler neticesinde diğer çalışmalara oranla elde edilen başarı değerinin arttı̆̆ tablolar ile ortaya konulmuştur.

Dünyada ve ülkemizde bilişim çağının getirdiği teknolojik gelişmeler neticesinde mahkeme ve yargı süreçlerinde dijital delillerin önemi ve kullanım oranı artmıştır. Buna paralel olarak suçlara ilişkin elde edilen dijital veri miktarında da hiçbir dönemde olmadığı kadar artma söz konusudur. Dolayısı ile artan veri miktarı, veri analiz süreçlerinin etkinliğini olumsuz etkilemektedir. Söz konusu olumsuzluğun giderilmesi ve müteakiben yargılama süreçlerinin hızlandırılması ancak dijital verilerin hızlı ve doğru analizi ile mümkündür. Bu kapsamda makalede ileri sürülen derin öğrenme modelinin, veri inceleme süreçlerinin etkinliğinin artırılması, söz konusu süreçlerin kısa sürede ve yüksek doğruluk oranında tamamlaması ve bunun neticesinde mahkeme süreçlerinde yaşanılan aksaklıkların ortadan kaldırılması adına önemli olduğu değerlendirilmektedir.

Makalede gerçekleştirilen çalışmanın kapsamı sadece görüntü verileri ile sınırlı tutulmuştur. Literatür taramasında da yer verildiği üzere farklı çalışmalarda derin öğrenme algoritmalarının farklı modeller oluşturmak koşulu ile görüntü verileri yanı sıra text, ses, video veya farklı format verilerde de adli bilişim uzmanlarına yardımcı bir elemen olarak kullanılabileceği değerlendirilmektedir. Ayrıca, adli bilişim uzmanlarına yardımcı bir eleman olmasının yanı sıra ileride gerçekleştirilecek çalışmalarda veri inceleme süreçlerinin tam otomasyonunun sağlanması kapsamında da farklı derin öğrenme modellerinin oluşturularak kullanılabileceği değerlendirilmektedir.

\section{V.SONUC}

$\mathrm{Bu}$ makalede, adli bilişimde veri inceleme süreçlerinin hızlandırılması ve insan müdahalesini en aza indirerek adli incelemelerde doğruluğunun arttırılması maksadı ile görüntü verilerinin yüksek doğruluk oranı ile sınıflandırılmasını sağlayan VGG16 tabanlı bir ağ modeli önerilmiştir. Model ile suça ilişkin olduğu değerlendirilen görüntü verileri, FloydHub geliștirme ortamında Keras ve TensorFlow derin öğrenme kütüphaneleri yardımı ile test edilmiştir. Elde edilen sonuç ve kullanılan hiper parametreler bu alanda gerçekleştirilen benzer çalışmalarla kıyaslanmış ve önerilen modelin diğer çalışmalara oranla ortalama \%5 oranında performans artışı sağladığı görülmüştür. Önerilen modelin, veri inceleme süreçlerinde insan hatasının en aza indirgenmesi ve veri analiz doğruluk oranlarının artırılması kapsamında adli bilişim uzmanları tarafından yardımcı bir yöntem olarak kullanılabileceği değerlendirilmektedir.

\section{KAYNAKLAR}

[1] V. Ganesh, "Artificial intelligence applied to computer," International Journal of Advance Research in Computer Science and Management Studies, vol. 5, no. 5, pp. 21-29, 2017.

[2] R.M.A. Mohammad, M. Alqahtani, "A comparison of machine learning techniques for file system forensics analysis," Journal of Information Security and Applications, vol. 46, pp. 53-61, 2019.

[3] W.D. Ferreire, C.B.R. Ferreire, G.C. Junior and F. Soares, "A review of digital image forensics," Computers and Electrical Engineering, vol. 85, no. 106685, 2020.

[4] Y. Başar, "Siber suç soruşturmalarında adli bilişim incelemeleri," Yüksek Lisans tezi, Fen Bilimleri Enstitüsü, Afyon Kocatepe Üniversitesi, Afyon, Türkiye, 2015. 
[5] N. Kansagara and S. Singh, "Thematically clustering in digital forensics text string searching: A survey,"International Journal of Advanced Research in Computer Science, vol. 8, no. 3, pp. 11281130, 2017.

[6] Y. Korkmaz ve B. Aytuğ, "Adli bilişim açısından ses incelemeleri," Science and Engineering Journel of Firat University, c. 30, s. 1, ss. 329-343, 2018.

[7] A.L.S. Orozco, C.Q. Huaman, D.P. Alvarez and L.J.G Villalba, "A machine learning forensics technique to detect post-processing in digital videos," Future Generation Computer Systems, vol. 111, pp. 199-212, 2020.

[8] D. Chaves, E. Fidalgo, E. Alegre, R.A. Rodriguez, F.J. Martino and G. Azzopardi, "Assessment and estimation of face detection performance based on deep learning for forensic applications," Sensors, vol. 20, no. 16, pp. 4491, 2019.

[9] G. Sreenu and M.A.S. Durai, "Intelligent video surveillance: A review through deep learning techniques for crowd analysis," J Big Data, vol. 6, no. 48, 2019.

[10] K. Fernandes, J.S. Cardoso and B.S. Astrup, "A deep learning approach for the forensic evaluation of sexual assault," Pattern Analysis and Applications, vol. 21, pp. 629-640, 2018.

[11] J.Y. Sun, S.W. Kim, S.W. Lee and S.J. Ko, "A novel contrast enhancement forensics based on convolutional neural networks," Signal Processing: Image Communication, vol. 63, pp. 149-160, 2018.

[12] M. Bedeli, Z. Geradts and E. Eijk, "Clothing identification via deep learning: Forensic applications,” Forensic Sciences Research, vol. 3, no. 3, pp. 219-229, 2018.

[13] R. Olmos, S. Tabik and F. Herrera, "Automatic handgun detection alarm in videos using deep learning," Neurocomputing, vol. 275, pp. 66-72, 2018.

[14] A. Fydanaki and Z. Geradts, "Evaluating OpenFace: An open-source automatic facial comparison algorithm for forensics," Forensic Sciences Research, vol. 3, no. 3, pp. 202-209, 2018.

[15] O. Mayer and M.C. Stamm, "Forensic similarity for digital images," IEEE Transactions On Information Forensics And Security, vol. 15, pp. 1331-1346, 2020.

[16] P. Glomb, M. Romaszewski, M. Cholewa and K. Domino, "Application of hyperspectral imaging and machine learning methods for the detection of gunshot residue patterns," Forensic Science International, vol. 290, pp. 227-237, 2018.

[17] M. Eriş, "Derin öğrenme yöntemleri kullanarak adli bilişim incelemelerinde delil çıkarımının gerçekleştirilmesi," Yüksek Lisans tezi, Fen Bilimleri Enstitüsü, Fırat Üniversitesi, Elazığ, Türkiye, 2018.

[18] R. Thakur and R. Rohilla, "Recent advances in digital image manipulation detection techniques: A brief review," Forensic Science International, vol. 312, no. 110311, 2020.

[19] S. Karakuş, "Derin öğrenme yöntemleri kullanarak dijital deliller üzerinde adli bilişim incelemesi," Yüksek Lisans tezi, Fen Bilimleri Enstitüsü, Fırat Üniversitesi, Elazığ, Türkiye, 2018.

[20] M. Babiker, E. Kararslan and Y. Hoşcan, "A hybrid feature-selection approach for finding the digital evidence of web application attacks," Turkish Journal of Electrical Engineering \& Computer Sciences, vol. 27, pp. $4102-4117,2019$. 
[21] M.K.Raji, "Digital forensic tools \& cloud-based machine learning for analyzing crime data," M.S. thesis, Department of Information Technology, Georgia Southern University, Georgia, USA, 2018.

[22] P.H. Rughani, "Artificial intelligence based digital forensics framework," International Journal of Advanced Research in Computer Science, vol. 8, no. 8, pp. 10-14, 2017.

[23] S. Costantini, G. Gasperis and R. Olivieri, "Digital forensics and investigations meet artificial ntelligence," Annals of Mathematics and Artificial Intelligence, vol. 86, pp. 193-229, 2019.

[24] A. Pandey,S. Mujmer, P. Gyarsiya and S. Kanungo, "A study on digital forensics using various algorithms for malware detection," International Journal of Advanced Research in Computer Science, vol. 9, no. 3, pp. 85-89, 2018.

[25] N.M. Karie, V.R. Kebande and H.S. Venter, "Diverging deep learning cognitive computing techniques into cyber forensics," Forensic Science International: Synergy, vol. 1, pp. 61-67, 2019.

[26] S.Sasank. (2019, February 01). Guns dataset [Online]. Available: https://www.kaggle.com/issaisasank/guns-object-detection.

[27] A.Kumar. (2020, February 02). Guns detection dataset (2nd ver.) [Online]. Available: https://www.kaggle.com/atulyakumar98/gundetection.

[28] Y.Khatri. (2020, October 02). Guns dataset (1th ver.) [Online]. Available: https://www.kaggle.com/khatriyash/csgo-guns-dataset.

[29] S.Shekhar. (2020, March 02). Knife dataset (1th ver.) [Online]. Available: https://www.kaggle.com/shank885/knife-dataset.

[30] V.Singh. (2018, October 08). Knife detection (1th ver.) [Online]. Available: https://www.kaggle.com/vijaysingh888/knife-detection. 